\title{
Variation in ovulation rate and litter size
}

\author{
G. E. BRADFORD and Y. M. BERGER
}

Department of Animal Science, University of California, Davis, California 95616, U.S.A.

\begin{abstract}
An increase in mean prolificacy is a goal for many sheep production systems, but it is also desirable that variation be minimized around the optimum value. Lambs born in litters of 3 or 4 can be reared with intensive management, but at higher input costs than for twins. Thus for a mean litter size (LS) goal of 2.0, producers desire the maximum possible proportion of twins with as few singles and litters of 3 or more as possible. Coefficients of variation for ovulation rate (OR) range from about $22 \%$ for Romanov to about $40 \%$ for Booroola Merinos; breed CV's for LS vary less. The most uniform LS's are achieved by populations with a uniform OR and high prenatal survival. Variability in Booroola populations results in part from segregation of a gene with large effect on $O R$, but variation is high within genotypes (FF or $\mathrm{F}+$ ). Among breeds where high prolificacy appears to be inherited quantitatively, there are differences in variability, with Romanov quite uniform, Finnsheep intermediate, and D'Man more variable. The possibility of a gene with large effect in the D'Man breed, in addition to many favorable quantitative genes for prolificacy, has not been ruled out. In general, these three breeds (and some others) transmit their prolificacy additively, making it possible to choose a wider range of mean prolificacy values by crossing and backcrossing with such breeds than by use of a major gene such as the Booroola. Data on variability of first and later generation crossbreds between non-prolific and different prolific breeds are now available.
\end{abstract}

Index words: ovulation rate, litter size, variation, Romanov, Booroola Merino, Finnsheep, D’Man, major gene 